Masthead Logo

Criticism

\title{
The Problem of Bodily Autonomy in the Cinematic Arts
}

Eliza Steinbock

Leiden University

Follow this and additional works at: https://digitalcommons.wayne.edu/criticism

\section{Recommended Citation}

Steinbock, Eliza () "The Problem of Bodily Autonomy in the Cinematic Arts," Criticism: Vol. 61 : Iss. 1 , Article 9.

Available at: https://digitalcommons.wayne.edu/criticism/vol61/iss1/9 
THE PROBLEM

OF BODILY

AUTONOMY IN

THE CINEMATIC

ARTS

Eliza Steinbock

Cinema's Bodily Illusions: Flying,

Floating, and Hallucinating by

Scott C. Richmond. 232 pp.

Minneapolis: University of

Minnesota Press, 2016. Paperback, $\$ 27.00$
In writing about the production of cinema's felt bodily illusions for moving through space, Scott C. Richmond sets himself the task of describing what cinema does to modulate human perception, how we attune to cinema, and how cinema operates above and below the representational level, that is, at the infrastructural and circuitous sensate levels that bodies plug into during a film encounter. The organizing investigation is into "the set of perceptual processes whereby we orient ourselves in and coordinate ourselves with the world" named proprioception, on which a selection of films "thematize and roughen our perceptual and, thus, embodied involvement with the world unfolding before us onscreen" (6). Richmond seizes on the paradoxical doubled body in proprioception that involves the self in the world and one's reflexive self-perception of that self. Polemically then, Richmond seeks to invigorate a "true phenomenology of perception" (69) for cinema studies that refocuses its attention on the viewer's thickened, resonant, and voluptuous experience of films by rehabilitating the concept of proprioception via James J. Gibson, Renaud Barbaras, and Maurice Merleau-Ponty in conjunction with aesthetics refashioned by Steven Shaviro after Kant and Whitehead (plus a late reading of Walter Benjamin) to account for what happens in the "technicity of the 
flesh" (a combination of Bernard Stiegler and Mark Hanson) during the coupling of viewer and cinematic technics. In this regard the book is a startling composition of theoretical frameworks from psychology, media theory, and continental philosophy that enriches every field it engages but most of all seems concerned with advancing the philosophical purchase of cinema for rethinking bodily being as partial, processual, relational.

I enjoyed the challenge of reading with Richmond across highly technical idioms to finesse new understandings of "the illusion of bodily movement through onscreen space, or cinematic kinesthesis" (18) by developing the central concepts of "proprioceptive aesthetics" (chapters 1 and 5), "ecological phenomenology" (chapter 3), the Epoche and the Écart (chapters 2 and 4), and "cinema as technics" (chapter 6). But, for me, it was Richmond's tackling of the simple idea that cinema presents an illusion to its audience that accomplished the difficult work of overturning hegemonic perspectives in film studies that adhere to philosophical skepticism and modernist debates on medium specificity. Typically scholars are concerned with the "illusion of reality" or the illusion of moving images (58). "Illusions that feel like illusions are not deceptive," he writes (58). This is against the field's skeptical bias that would assume cinema is a system for representing objects that fool the spectator into believing they actually appear. Richmond insists that on the nonrepresentational level, one's proprioceptive grasp of movement abides even when one knows they are not actually moving. Attending to the illusion of flying sidelines the problem of correspondence onscreen and off that entangles debates on film's photographic realism, also in comparison with digital technologies. Instead bodily illusions of proprioceptive movement index "the always palpable divergence between ordinary perception and its technical modulation by the cinema" (70). I was convinced that the overriding cinematic illusion is the proprioceptive fun of being "compelled, even captivated, by the cinema's aberrant information" that I accept (however provisionally) due to what Merleau-Ponty describes as the perceptual faith that conditions my inherence in this world, which is given to the world onscreen and off (89).

The "I" that foregrounds his spectatorial position leads the reader into thick description of select scenes and illusory effects in Marcel Duchamp's Anémic Cinéma (1926), Tony Conrad's The Flicker (1965), Stanley Kubrick's 2001: A Space Odyssey (1968), Godfrey Reggio's Koyaanisqatsi (1982), and Alfonso Cuarón's Gravity (2013) that together amass a range of periods, genres, and technical supports. 
The chapters that center on these filmic examples each offer an elaboration of what is at stake in the deconstruction of dualist concepts for embodiment such as the visible and invisible with flesh, and of the bodily ambivalences between what's onscreen and offscreen, real or hallucinatory, or the spectatorial position between active and passive. Hence, it struck me as somewhat odd that Richmond declines the explicitly feminist standpoint of Vivian Sobchack in The Address of the Eye (1992) or the postcolonial critique of Laura U. Marks in The Skin of the Film (1999). He announces in the introduction that "the phenomenological remit of this book is to bracket its representational dimension - and thus also to suspend most of our ways of attending to the social, political, cultural, and ideological work of the cinema," which necessarily involves "foregoing politics" until the final sixth chapter in which Walter Benjamin's revampment of media theory for the problems of technological modernization is brought into play (18). Despite this said bracketing, I detect an overarching political program that would be integral to feminist and postcolonial projects. In theorizing the more general and pervasive way in which cinema modulates a viewer's body into experiencing the perceptual sensations of flying, floating, and hallucinating, Richmond foundationally takes it that cinema undercuts the notion of bodily autonomy.

This is to say, the book stridently takes on any overt or covert allegiance to an individual's autonomy in relation to technology, language, and the world of representation/ art. The burden of the controlled, separate individual who must communicate via "critical athleticism" crops up in dominant frameworks for aesthetics especially within modernism. This kind of film critic couches a skeptical subject who properly differentiates an object from its appearance and their body from the world at large. In bolstering this posture, Richmond might have expanded on feminist, transgender, and queer theory insights and interventions within phenomenological body studies that our bodies are not ours alone, nor are we only our bodies (cf. Liz Grosz, Jay Prosser, Judith Butler). The problem of asserting bodily autonomy is - let me just say it - a problem of White European Colonizing Man as Human, a sickly hangover from Enlightenment thinking with which Richmond himself quarrels. Indeed, the problem of bodily autonomy is the lack thereof not just for some subjects but for all subjected to the false ideal therein.

Taking another tack, Cinema's Bodily Illusions quietly announces a fun cinema whose tickling, sensitizing technicity in the flesh teases the unbounded viewer-a far cry from Baudry's unitary and 
masterful viewer plugged into the cinematic apparatus. I mean a fun cinema in the many senses of enjoyable, foolish, silly, humorous, strange, odd, or causing perplexity (terms that Richmond uses). The book's achievement of reintroducing amusement and wonder also goes far in countering the negative affects towards illusions, or even towards the potentially damaging element of cinematic technologies, which underlie apparatus theories and stretch back to concerns over stimulating optical toys and spellbinding phantasmagoria. In his realm of admittedly idiosyncratic film viewing, we encounter this fun cinema as one of pleasure, especially in submission; examples include thin and anemic cinema that give rise to cute experiences, evanescent, and terrifying feelings, and other giddy, funny, and weird cinema that instantiates thrilling, panic-inducing, meditative, slippery, and vertiginous moments. Although Richmond focuses on the how of cinematic coupling with human perceptual systems, rather than the why, clearly the underlying assumption is that we do so in whatever format because they are inexplicably fun. The book's aim to explicate the workings of such fun aesthetics, in my experience, adds to rather than detracts from better understanding why "I delight in . .." certain cinematic affects. Cinema studies would do well to attend to an outright laugh, a giggle, or to taking pleasure in a "frankly psychedelic" effect or the yielding to the training of proprioceptive aesthetics. Richmond succeeds best in presenting dramatized and dedramatized scenes of cinephilia predicated on a non-sovereign body: "I am neither self-possessed nor self-sufficient. I am open to the world not only perceptually but also technically" (17).

Eliza Steinbock is Assistant Professor of Film and Literary Studies at Leiden University. They were recently published in Feminist Media Studies, Routledge Companion to Cinema and Gender, and co-edited Somatechnics on "Cinematic Bodies." Their first book is Shimmering Images: Trans Cinema, Embodiment and the Aesthetics of Change (Duke University Press, March 2019). www.elizasteinbock.com. 